
\title{
25 Research Square \\ Validation of Sinhala Version of Brief COPE Scale in Patients with Cancer in Sri Lanka
}

Eranthi Weeratunga ( $\square$ eranthiw@ahs.ruh.ac.Ik)

University of Ruhuna

Chandanie Senadheera

University of Ruhuna

Manjula Hettiarachchi

University of Ruhuna

Bilesha Perera

University of Ruhuna

\section{Research Article}

Keywords: Brief COPE, cancer, coping skills, reliability, validity

Posted Date: December 29th, 2021

DOI: https://doi.org/10.21203/rs.3.rs-1205154/v1

License: (9) This work is licensed under a Creative Commons Attribution 4.0 International License.

Read Full License 


\section{Abstract \\ Background}

Coping strategies are essential in the cancer management/recovery process and show an integral part in patients with cancer globally. In Sri Lanka, validated scales to measure coping are scarce. This study was examined the Sinhalese version of the Brief COPE for its psychometric properties.

\section{Methods}

This scale is self-administered (28 items) and consists of adaptive and maladaptive coping strategies; divided into 14 subscales. Cancer patients were registered 'first come - first serve' basis using their appointment register at the Radiotherapy Unit, Oncology ward, Teaching Hospital, Karapitiya, Galle, Sri Lanka. They were requested to complete the Sinhalese version of the Brief COPE and demographic details. Test-retest reliability was checked using the same subjects two weeks later. Factorial validity was performed using exploratory factor and principal component analysis. Results were regarded as statistically significant if $p<0.05$.

\section{Results}

The mean $( \pm S D)$ age of the sample was $61( \pm 12)$ years. The mean adaptive coping $( \pm S D)$ and maladaptive coping were $37.50( \pm 8.14)$ and $17.10( \pm 2.44)$ respectively. The internal consistency of the overall scale was good (Cronbach's alpha - 0.819). Adaptive and maladaptive coping showed a high Cronbach's alpha (0.861 and 0.396$)$. The test-retest reliability was found to be 0.66 . The Sinhala version of $B C$ was found to have a negative correlation with the CES-D scale but was positively correlated with the WHOQOL-BREF questionnaire. Seven factors were extracted.

\section{Conclusion}

The Sinhala version of the Brief COPE is a valid and reliable tool to assess coping strategies among patients with cancer. The findings of this study would let the health authorities get an understanding of coping strategies among patients with cancer; and the impact on cancer victims and family members to relieve their suffering.

\section{Background}

Cancer is the second leading cause of death in the world and similar trends have been reported in Sri Lanka too [1, 2]. Individuals diagnosed with incurable cancer face a life-threatening stressor; may react to the stressful, unexpected circumstances such as diagnosis of cancer differently, elicits various coping responses [3]. 'Coping' is the process by which people manage stress or attempt to manage stressful 
demands (external or internal) [4, 5]. Distress, depression, anxiety, hopelessness, fear, and aggression have a great impact on cancer as in the past literature [6, 7].

Cancer patients and family members should pay more attention to the psychological and social aspects of the patient to enable them to cope with the disease and its treatment [8]. It was found that more personal and social resources were needed for the psychological and physical adjustment of breast cancer during that time for coping $[6,9,10]$. Studies have focused on different coping strategies among patients with several types of cancer; also, a variety of self-report tools have been used to assess coping strategies worldwide. Limited research was done to measure coping strategies in cancer patients and validated scales to measure coping were scarce in Sri Lanka compared to the western countries [11]. Carver et al. established the full COPE comprises 60 items, to minimize the time taken to complete the scale, developed Brief COPE scale (BC) [10].

Assessing coping strategies in patients with cancer facilitates the healthcare providers to get an insight into the impact of coping on cancer patients. Such an understanding is vital in making decisions about future care, different treatment, and managing complications faced by cancer patients and their family members, formal/informal caregivers, etc. Further, a culturally adopted scale would be more important to any population group in Sri Lanka to assess their coping strategies and find out more favorable/healthy coping methods as well as minimize ineffective coping mechanisms like substance use, etc.

The purpose of this study was to examine the psychometric properties of the BC scale for patients with cancer treated at a tertiary care hospital in Southern Sri Lanka.

\section{Methods}

Cross-cultural adaptation guidelines were followed as the instructions of Beaten et al. [12] and the World Health Organization (WHO) [13]; forward translation of the original version, expert panel discussion (e.g., oncologists, clinical psychologists, clinician, professor in behavioral sciences, senior lecture in nursing), back-translation, pre-testing, and cognitive interviewing. A preliminary version was developed after reviewing both forward and backward translation by the expert committee. Finally, a modified version of the $\mathrm{BC}$ was understood easily; the panel of content experts has ensured the content validity of the scale. Final Sinhalese version of Brief COPE (S-BC) scale [See additional file 1] was developed.

This BC scale has 28- items; contains 14 subscales with only two items on each scale, graded by the fourpoint Likert scale. The responses to the items were $1=$ 'I have not been doing this at all', $2=$ 'I have been doing this a little bit, $3=$ 'I have been doing this a medium amount' and $4=$ 'I have been doing this a lot. The higher score of the subscale exhibits more likely the coping methods were used by the respondents. Cronbach's alpha of original BC was higher than 0.6 for 11 of the 14 subscales. The first eight subscales (16 items) were titled 'adaptive coping strategies, and the other six subscales (12 items) were named 'maladaptive coping strategies'[10]. A higher score indicates a higher adaptive (score ranges from 0-48) and maladaptive coping (score ranges from 0-36). In terms of usage, Carver's scale has been widely used in different countries and has been shown good psychometric properties [14 - 16]. 
Internal consistency/reliability of the S-BC was examined using Cronbach's alpha coefficient for an overall score of the S-BC and subscales considering the accepted standard cut-off for internal consistency as 0.60 or above [17]; considered as satisfactory internal consistency.

The test-retest reliability was examined using intra-class correlation coefficient (ICC) using the scores of scales in the first time and second time administrations (administered the same questionnaire after two weeks of first administration among the same 40 cancer patients). Pearson's correlation coefficient was added to examine test-retest reliability.

Further, Pearson's correlation coefficient was applied to check the concurrent validity of the S-BC scale and other standards scales (using correlations between the subscales themselves and the total score of the S-BC scale and standards scales). Convergent validity was assessed by item-subscale correlation considering a higher correlation of each item with their respective subscale. In addition, both WHOQOLBREF and CES-D scales were used to examine convergent and discriminant/divergent validity assumed that participants who have higher coping used to have higher QoL and lower depressive symptoms; all applications were able to confirm the criterion validity of the scale.

Factorial validity of the S-BC was assessed using exploratory factor analysis (EFA). Factor analysis (FA) was performed using principal component analysis (PCA) with Varimax rotation (Kaiser normalization/Kaiser-Meyer - Olkin (KMO)). Bartlett's Test of Sphericity should reach statistical significance $(p<0.001)$ and Commonalities Coefficients should be high $(>0.6)$ [18].

The number of extracted components was determined by the Scree plot, percentage of variance explained by each component, number of Eigenvalues over one (Kaiser-Guttman rule), and consideration of prior psychometric Brief COPE analysis. Items were considered representative of a component if their item loading was $\geq 0.40$ and in the cross-loading items, the factor, which had a higher loading value, was taken the respective factor [19].

A total of 40 cancer patients at the Radiotherapy unit, Oncology ward, Teaching Hospital, Karapitiya (THK) in Southern Sri Lanka were enrolled. Informed written consent was obtained from the patient before the data collection and participation in the study was voluntary. The sample size was considered supposing the correlational coefficient is about 0.45 for the Brief COPE using the subsequent formula $\mathrm{N}=$ $[(Z a+Z \beta) / C] 2+3$. The calculated sample size was 36 and adding $10 \%$ for the non-respondents, the final sample size was 40 [19].

Baseline characteristics of the cancer patients were obtained using an interviewer-administered questionnaire and the diagnosis cards of the patients. Centre for Epidemiological Studies - Depression scale (20 item- CES-D) [20] and the World Health Organization-Quality of Life - Brief scale (26 itemWHOQOL-BREF) [21] were administered along with the newly adopted S-BC scale among 40 cancer patients by the principal investigator. Participants were informed to complete tools; the S-BC, CES-D, and WHOQOL-BREF which were previously validated in the Sri Lankan context. 
The CES-D is a 20-item, short and self-report scale, which was originally developed to assess depressive symptomatology in the general population worldwide [20] during the 'past week'. Each question has 04 responses from 0 (rarely or none of the time) to 3 (most or all of the time). The total score of the CES-D scale ranges from 0 (no depressive symptoms) to 60 (high level of depressive symptoms), where higher scores indicate the presence of more depressive symptomatology. This scale was validated in freely used in Sri Lanka [22].

The WHOQOL-BREF is a 26-item scale comprised of 04 domains; physical, psychological, social, and environmental, and originally developed to measure the QoL [21]. The higher values indicated a higher level of QoL. The scale WHOQOL-BREF has been validated in the Sri Lankan setting and used freely available in many studies [23].

Data analysis was done using SPSS 25.0 (IBM statistics, Inc., Chicago). The level of significance was accepted at $p<0.05$. Descriptive statistics were used to present baseline characteristics of cancer patients. Correlation coefficient values between 0.10 and 0.29 were considered low, between 0.30 and 0.49 were considered medium, and between 0.50 and 1.00 were considered high and as very strong correlation [19].

Ethical approval was obtained from the Ethics Review Committee of the Faculty of Medicine, University of Ruhuna and permission to recruit patients by healthcare setting. For the scale validation process, permission was obtained from the original authors of Brief COPE.

\section{Results}

Among 40 cancer patients, $53.0 \%(n=21)$ were males, $88.0 \%$ was married and $75.0 \%$ was employed (Table 1). The mean ( $\pm S D)$ age of the sample was 61.03( \pm 11.70$)$ years. The mean $( \pm S D)$ score of the adaptive coping was $37.50( \pm 8.14)$ and maladaptive coping was $17.10( \pm 2.44)$ as in the below. Mean $( \pm S D)$ S-Brief COPE scores of individual items are shown (Table 1). Of the Adaptive coping, the highest score was $6.87 \pm .1 .68$ for item-1 'Instrumental support'. As in the maladaptive scale, the highest score was $5.08 \pm 1.40$ for item- 1 'Self-distraction'. The reliability of all subscales was checked and reliability scores of the S-BC scale ranged from 0.01 to 1.00 (Table 1). Due to the zero variance, three items were detached spontaneously from the reliability analysis (item 18-I have been making jokes about it, item 28-I have been making fun of the situation, item 3-I have been saying to myself "this is not real"). Then retained 25items were checked for reliability/internal consistency.

Reliability of the total/overall scale (25 items) was found to be good (Cronbach's alpha 0.819 ); reliability of the adaptive scale (14 items) and maladaptive scale (11 items) was 0.861 and 0.396 respectively.

In both phases, adaptive and maladaptive subscales of the S-BC had high Cronbach's alpha; it was 0.793 and 0.788 respectively. Test-retest reliability was higher for adaptive $(r=0.657, p<0.01)$ and maladaptive scales $(r=0.651, p<0.01)$. Test-retest reliability measured with ICC between 1st and subsequent administration of adaptive and maladaptive scores reported higher ICC; adaptive: ICC $=0.65,95 \% \mathrm{Cl}=$ 
$0.43-0.80, p<0.001$, maladaptive: $\mathrm{ICC}=0.65,95 \% \mathrm{Cl}=0.42-0.79, p<0.001$. These results suggest that the $\mathrm{S}-$ $\mathrm{BC}$ scale has acceptable reliability over time.

Adaptive coping was inversely correlated with CES-D scores (discriminant / divergent validity) whereas maladaptive coping was positively correlated with CES-D scores that exhibited the convergent validity of the S-BC (Table 2).

Adaptive coping, total QoL, and four domains of WHOQOL-BREF (theoretically related variables) were positively associated with each other indicating convergent validity of the S-BC. Maladaptive coping was significantly and negatively correlated (discriminant/divergent validity) with total QoL, physical, and social QoL domains whereas not significantly associated with psychological and environmental domains.

PCA revealed seven factors contrast to the original scale, with Eigen value exceeding 1explaining cumulative variance of $78.68 \%$ (factor $1 ; 24.97 \%$, factor $2 ; 42.82 \%$, factor $3 ; 52.13 \%$, factor $4 ; 61.37 \%$, factor $5 ; 67.37 \%$; factor $6 ; 73.35 \%$, factor $7 ; 78.68 \%$ ) (Table 3; Figure. 1 ).

Without three items, other all items had included in the factor structure. But as in the original taxonomy, 14 subscales were unable to fragment due to the loading patterns of each item [10]. The minimum item loading was 0.57 (8A Trying to get healed); 11 th items were cross loaded on more than one factor in a significant figure (e.g., 12B, 6B, 8A, 3A, 2A, 1B, 7A, 8B, 1A, 11A and 7B).

Those cross-loaded items were included to one factor according to their higher loadings and the appropriate interpretation of the item. According to the previous studies/ conceptual scales and relevant explanations of the items, those were re-assigned/ included into respective subscales/ 7 subscales.

The $1^{\text {st }}$ extracted factor was loaded by six items of five subscales of the original Brief COPE (denial, selfblame, positive reframing, substance use, and two items from the behavioral disengagement subscale). Overall, this factor can be named as the "Avoidance and Behavioral disengagement". The $2^{\text {nd }}$ factor was included the six items of four subscales (acceptance, planning, positive reframing, using instrumental support, and two items from the religion); can be constructed as the "Religion and Acceptance". $3^{\text {rd }}$ factor consisted of self-distraction, acceptance, using emotional support, and instrumental support; these factors can be concluded as "Seeking support" scales. $4^{\text {th }}$ factor consisted of the three items of three subscales (planning, active coping, and self-distraction subscales) and was named "Planning". $5^{\text {th }}$ factor corresponded to substance use and venting subscale; can be constructed "Substance use and Venting" subscales. The $6^{\text {th }}$ factor contained only one item of self-blame subscale was named "Self-blame". The $7^{\text {th }}$ factor consisted of venting, using emotional support, and active coping subscales; can be constructed as the" Active/positive coping". Among seven factors, only four factors had scored fair Cronbach's alpha (Table 3 ) and the newly adopted structure resulted in 0.57 of Cronbach's alpha (07-factor structure).

\section{Discussion}


This study validated the Sinhalese BC scale into Sri Lankan setting. Coping strategies which are used by patients with cancer were not much focused in Sri Lankan setting. Therefore, validation of the Brief COPE scale to the Sri Lankan setting was vital and imperative.

This study obtained good internal consistency and test-retest reliability of the S-BC when operationalized as two subscales. Cronbach's alpha of the overall scale was 0.819 whereas had not been shown in some studies $[10,24]$. Adaptive coping had a high Cronbach's alpha of 0.861 whereas maladaptive coping had low reliability $(0.396)$.

A high-reliability coefficient for the subscales was not much detected throughout the current study that contrasts from the results of others [10]. In our study, most of the subscales had shown lower internal consistencies whereas three subscales had scored higher internal consistency: instrumental support (0.85), emotional support (0.70), religion (0.79), and behavioral disengagement (1.00). Acceptable internal consistencies had conveyed for most of the subscales elsewhere, especially as in the original Brief COPE study $[10,24]$. Nevertheless, others had reported better internal consistencies for maladaptive coping subscales [10] which is the difference from our results. Cronbach's alphas were tested for both phases; adaptive and maladaptive coping had better reliabilities ( $\ .785)$. Test-retest reliability was also high due to the homogeneity and stability of the scale over two weeks period (reliability of 2 major subscales $=\mathrm{r} \otimes .650, p<0.01)$.

Correlations between S-Brief COPE, CES-D, and WHOQOL-BREF were performed to confirm the criterion validity of the scale. Correlation findings among S-BC, CES-D, and QoL were presented reverse association; evidence of measuring different constructs or concepts. As the correlation findings of the S$\mathrm{BC}$ scale, similar construction among items in the subscale had a similar correlation (convergent validity). Different structures amongst different subscales or correlations of items and dissimilar subscales had lower correlation (discriminant/divergent validity). Those were significant clues for high criterion validity between different subscales in the same tool.

Even though the factor structure of the scale had been established already, plentiful studies had investigated [24]. Seven factors were extracted from the EFA in the current study and each subscale/item (25 items) was included into relevant seven factors collectively (avoidance/behavioral disengagement, religion/acceptance, seeking support, planning, substance use/venting, self-blame, active/positive coping). A similar number of factors was obtained by Hagan et al. [3] and labeled as self-blame, acceptance, denial, emotional support, positive reframing, active, and behavioral disengagement. Due to the dissimilar constructions of extracted factors in the current study; one factor was made as to the independent factor and consisted of an item of the single subscale (6th factor -self-blame comprised with item 13 of the self-blame subscales), while some factors incorporated clusters of different subscales and created broader domains (3rd factor - seeking support contained with items of self-distraction, acceptance, using emotional support and instrumental support subscales). These categories of broader dimensions and independent factors (e.g., - religion, substance use, etc.) were revealed in previous studies also $[24,25]$. These two studies had established broader dimensions for some factors; the study of 
Kapsou et al. [24] had broader factors for 1 (Active/positive coping), 4 (seeking support), etc. and 1 (problem-solving/acceptance), 2 (negative venting/avoidance), 4 (self-blame/denial), and 6 (humor/selfdistraction) broader domains were comprised in the Su et al. [25] also in line with our results that we were able to progress broader dimensions such as 1 (avoidance/behavioral disengagement), 2 (religion /acceptance), and 5 (substance use/ venting) in this study.

Furthermore, emotional and instrumental support subscales had concluded into one factor (seeking support) as others [24, 25]. Additionally, venting was loaded into the same factor in one study [25] whereas acceptance and self-distraction items were loaded into the 'seeking support' factor in our study. Religion as an independent factor of the above two studies $[24,25]$ study performance as a broader factor (religion and acceptance) and comprised different subscales like religion, acceptance, planning, positive reframing, and instrumental support.

Denial and self-blame subscales were clustered into the 4th factor (self-blame/denial) [25] whereas selfblame was extracted into 1st (active/positive coping) and 8th factors (expression of negative feelings) of the study of Kapsou et al. [24] Self-blame had loaded into 1st factor as well 6th factor and denial were extracted into 1st factor in the present study. 'Substance use' had not a distinct factor in the study of Su et al. [25] but comprised into 'negative venting/avoidance' dimension. Independent factor had established for 'substance use' [25] whereas a broader dimension was established for substance use (substance use/venting) in our study.

Further, most of the adaptive and maladaptive coping subscales had mixed up in the different studies and established new factors. Yet new factors which interrelated to adaptive coping (problem-solving/ acceptance, support seeking, the reliance on spirituality, etc.) had established in previous studies [24, 25] as comparable in this study (religion/acceptance, planning, active/positive coping, seeking support, etc.,). Accordingly, the new factor structure had enough support to the original arrangement of the Brief COPE.

\section{Conclusion}

The Sinhalese version of the Brief COPE scale was found to be a reliable and valid screening tool that can be used to measure coping strategies among patients with cancer in Sri Lankan clinical setting. The findings of this study would let the health authorities get an understanding of coping strategies among patients with cancer, and the impact on cancer victims and family members to relieve their suffering. Future research with higher numbers of participants and in different settings/languages will be recommended.

\section{Abbreviations}

Brief COPE

Brief Coping

SD 
Standard Deviation

CES-D

Centre for Epidemiological Studies-Depression scale

WHOQOL-BREF

World Health Organization-Quality of Life-Brief scale

$\mathrm{BC}$

Brief COPE

WHO

World Health Organization

S-BC

Sinhalese version of Brief COPE

ICC

Intra-class correlation coefficient

EFA

Exploratory Factor Analysis

FA

Factor analysis

PCA

Principal component analysis

KMO

Kaiser-Meyer - Olkin

THK

Teaching Hospital Karapitiya

QoL

Quality of Life

SPSS

Statistical Package for the Social Sciences

$\mathrm{Cl}$

Confidence Interval

\section{Declarations}

\section{Acknowledgement}

The authors thank all participants in this study, former consultant oncologists (Dr. Upul Ekanayaka), and consultants who gave their permission to conduct the study at the cancer unit, Teaching HospitalKarapitiya, Galle, administrative staff and healthcare professionals at cancer unit, Teaching HospitalKarapitiya, Galle, Sri Lanka. 


\section{Authors' contributions}

EW conceived and designed the study as part of her MPhil thesis, under the supervision of CS, MH and BP. EW reviewed the literature and collected the data. EW performed statistical analyses and prepared the first draft of the manuscript. CS, MH and BP contributed to the design of the study and the interpretation of the findings. BP guided and supervised the data collection and statistical analysis, and the supported with the preparation of subsequent drafts of the manuscript. All authors critically revised the manuscript and contributed towards the final draft. All authors have read and approved the final version of the manuscript.

\section{Funding}

Funding for the research project was granted by the Faculty Research Grant, Faculty of Medicine, University of Ruhuna, Galle, Sri Lanka.

\section{Availability of data and materials}

The datasets used and/or analyzed during the current study are available from the corresponding author on reasonable request.

\section{Ethics approval and consent to participate}

Ethical approval for the study was obtained from the Ethics Review Committee, Faculty of Medicine, and the University of Ruhuna. Permission was granted from the Director of THK, Consultants, and Sisters/InCharges to conduct this research in the Oncology ward and informed written consent was obtained from all the participants included in the study during

the completion of the questionnaire, participants were able to ask questions. All participants read and offered signed informed consent before joining in the study.

\section{Consent for publication}

Not Applicable.

\section{Competing interests}


The authors declare that they have no competing interests.

\section{Author details}

${ }^{1}$ Department of Nursing, Faculty of Allied Health Sciences, University of Ruhuna, Galle, Sri Lanka.

${ }^{2}$ Department of Psychiatry, Faculty of Medical Sciences, University of Ruhuna, Galle, Sri Lanka. ${ }^{3}$ Nuclear Medicine Unit, Faculty of Medicine, University of Ruhuna, Galle, Sri Lanka. ${ }^{4}$ Department of Community Medicine, Faculty of Medicine, Galle, University of Ruhuna.

\section{References}

1. GLOBOCAN. New Global Cancer Data. 2020. https://www.uicc.org/news/globocan-2020-new-globalcancer-data.

2. Cancer Registry. Cancer Incidence Data-2001-2005 Sri Lanka. 2009. http://203.94.76.60/cancer/Cancer\%20registry\%202005.pdf.

3. Hagan TL, Fishbein JN, Nipp RD. Coping in Patients with Incurable Lung and Gastrointestinal Cancers: A Validation Study of the Brief COPE. J Pain Symptom Manage 2017; 53(1): 131-138. https://doi.org/10.1016/j.jpainsymman.2016.06.005.

4. Folkman S, Lazarus RS. The relationship between coping and emotion: implications for theory and research. Social Science Medicine 1988; 26(3): 309-317. https://doi.org/10.1016/02779536(88)90395-4.

5. Carver CS, Scheier MF, Weintraub JK. Assessing coping strategies: a theoretically based approach. Journal of Personality and Social psychology 1989; 56(2): 267-283. https://psycnet.apa.org/doi/10.1037/0022-3514.56.2.267.

6. Yuan L, Pan B, Wang W. Prevalence and predictors of anxiety and depressive symptoms among patients diagnosed with oral cancer in China: a cross-sectional study. BMC Psychiatry2020;20: 394409. https://bmcpsychiatry.biomedcentral.com/articles/10.1186/s12888-020-02796-6.

7. Allegany HA, Soltan MR, Soliman SS. Anxiety, depression and perceived stress among breast cancer patients: single institute experience. Middle East Current Psychiatry 2020; 27(29):1-10. https://mecp.springeropen.com/articles/10.1186/s43045-020-00036-x.

8. Mukwato KP, Mweemba P, Makukula MK, Makoleka MM. Stress and Coping Mechanisms Among Breast Cancer Patients and Family Caregivers: A Review of Literature. Medical Journal of Zambia 2010; 37(1), 40-45. https://www.ajol.info/index.php/mjz/article/view/75653.

9. Helgeson VS, Snyder P, Seltman H. 2004. Psychological and Physical adjustment to breast cancer over 4 years: identifying distant trajectories of change. Health Psychology 2004; 23(1):3- 15. https://doi.org/10.1037/0278-6133.23.1.3. 
10. Carver CS. You want to measure coping but your protocol's too long: consider the brief cope. International Journal of Behavioural Medicine 1997; 4(1):92-100. https://doi.org/10.1207/s15327558ijbm0401_6.

11. Mudduwa L, Punchihewa G. Psychological impact of breast cancer: a study done in a Sri Lankan setting. Galle Medical Journal 2011; 16(1): 16-21. https://doi.org/10.4038/gmj.v16i1.2904.

12. Beaton DE, Beaton D, Bombardier C. Guidelines for the Process of Cross-Cultural Adaptation of SelfReport Measures. Spine (Phila Pa 1976) 2000; 25 (24): 3186-91. https://pubmed.ncbi.nlm.nih.gov/11124735/.

13. World Health Organization. Process of translation and adaptation of instruments. Geneva: World Health Organization 2016. http://www.who.int/substance_abuse/research_tools/translation/en/.

14. Bai S, Liu J, Bo Y. Reliability and validity of the brief cope scale among offenders in China. Sciendo 2020; 5: 5. https://doi.org/10.2478/9788395669682-001.

15. Ornek OK, Temel GY. Reliability and Validity of the Turkish Version of the Brief Scales for Coping Profile in Textile Workers. Nővér 2018; 31(2):1-40. https://doi.org/10.31031/COJNH.2017.01.000508.

16. Rand KL, Cohee AA, Monahan PO, Wagner LI, Shanahan ML, Champion VL. Coping Among Breast Cancer Survivors: A Confirmatory Factor Analysis of the Brief COPE. J Nurs Meas 2019; 27(2): 259276. https://doi.org/10.1891/1061-3749.27.2.259.

17. Laksmita OD, Chung M-H, Liao Y-M. Multidimensional Scale of Perceived Social Support in Indonesian adolescent disaster survivors: A psychometric evaluation. PLoS ONE 2020; 15(3): e0229958. https://doi.org/10.1371/journal.pone.0229958.

18. Field A. Discovering statistics using IBM SPSS statistics: Sage; 2013.

19. Bland M. An introduction to medical statistics, 3rd ed. Oxford: Oxford University Press; 2000.

20. Radloff LS. The CES-D scale: a self-report depression scale for research in the general population. Appl Psychol Meas 1977; 1(3):385-401. https://doi.org/10.1177/014662167700100306.

21. World Health Organization Quality of Life Assessment Group (WHO-QOL group). Development and general psychometric prospects. Social Sci Med 1988; 46(12): 1569-85. https://doi.org/10.1016/s0277-9536(98)00009-4.

22. Ferdinando KD. Prevalence and correlates of depression in adults of 25-45 years in Kalutara DDHS area. MD-Community Medicine (PGIM). University of Colombo, Sri Lanka 2006; 129. http://192.248.21.144/handle/1/978.

23. Kumarapeli V, Seneviratne RA, Wijeyaratne CN. Validation of WHOQOL-BREF to measure the quality of life among women with polycystic ovary syndrome (PCOS). SL J Col of Com Physi 2016 11(2): 01-9. https://doi.org/10.4038/jccpsl.v11i2.8252.

24. Kapsou M., Panayiotou G., Kokkinos CM. Dimensionality of coping: an empirical contribution to the construct validation of the Brief-COPE with a Greek-speaking sample. Journal of Health Psychology 2010; 15:215-229. https://doi.org/10.1177/1359105309346516. 
25. Su X-Y, Lau J-T, Mak W-W. A preliminary validation of the Brief COPE instrument for assessing coping strategies among people living with HIV in China. Infect Dise of Pover2015; 4(41):10. https://idpjournal.biomedcentral.com/articles/10.1186/s40249-015-0074-9.

\section{Tables}

Table 1 Characteristics of the study participants $(\mathrm{N}=40)$ 


\begin{tabular}{|c|c|c|}
\hline Characteristics/variables & Categories & $\mathrm{N}(\%)$ \\
\hline Age & $\begin{array}{l}<60 \text { Years } \\
\square 60 \text { Years }\end{array}$ & $\begin{array}{l}20(50.0) \\
20(50.0)\end{array}$ \\
\hline Gender & $\begin{array}{l}\text { Male } \\
\text { Female }\end{array}$ & $\begin{array}{l}21(52.5) \\
19(47.5)\end{array}$ \\
\hline Marital status & $\begin{array}{l}\text { Married } \\
\text { Unmarried/ single }\end{array}$ & $\begin{array}{c}35(87.5) \\
5(12.5)\end{array}$ \\
\hline Education & $\begin{array}{l}\text { No schooling } \\
\text { Primary education (Grade 1-5) } \\
\text { Secondary education (Grade 6-12) }\end{array}$ & $\begin{array}{l}5(12.5) \\
9(22.5) \\
26(65.0)\end{array}$ \\
\hline Employment & $\begin{array}{l}\text { Employed } \\
\text { Unemployed }\end{array}$ & $\begin{array}{l}30(75.0) \\
10(25.0)\end{array}$ \\
\hline Cancer types/locations & $\begin{array}{l}\text { Head \& Neck cancer } \\
\text { GI organs } \\
\text { Lungs } \\
\text { Bones } \\
\text { Breast } \\
\text { Prostate } \\
\text { Lymph node } \\
\text { Site unknown } \\
<12 \text { months } \\
\square 12 \text { months }\end{array}$ & $\begin{array}{c}2(5.0) \\
12(30.0) \\
1(2.5) \\
3(7.5) \\
3(7.5) \\
1(2.5) \\
3(7.5) \\
15(37.5) \\
8(20.0) \\
32(80.0) \\
\end{array}$ \\
\hline $\begin{array}{l}\text { Measurements } \\
\text { S-Brief COPE- Adaptive coping }\end{array}$ & Cronbach's alpha $(\alpha)$ & $\begin{array}{l}\text { mean } \pm \text { SD } \\
37.50 \pm 8.14\end{array}$ \\
\hline \multirow{2}{*}{ S- Brief COPE- Maladaptive coping } & $\begin{array}{l}\text { Instrumental support (range 2-8) } 0.85 \\
\text { Use of emotional support0.70 } \\
\text { Planning0.48 } \\
\text { Active coping } 0.55 \\
\text { Religion0.79 } \\
\text { Acceptance } 0.01 \\
\text { Positive reframing-0.07 } \\
\text { Humor- }\end{array}$ & $\begin{array}{l}6.87 \pm .1 .68 \\
6.68 \pm 1.73 \\
5.30 \pm 1.80 \\
4.75 \pm 1.69 \\
4.65 \pm 2.00 \\
4.00 \pm 1.03 \\
3.25 \pm 1.27 \\
2.00 \pm 0.00\end{array}$ \\
\hline & $\begin{array}{l}\text { Self-distraction (range 2-8) } \\
\text { Venting0.09 } \\
\text { Substance use0.52 } \\
\text { Self-blame-0.06 } \\
\text { Denial- } \\
\text { Behavioral disengagement1.00 }\end{array}$ & $\begin{array}{l}17.10 \pm 2.44 \\
5.08 \pm 1.40 \\
3.60 \pm 1.21 \\
2.20 \pm 0.56 \\
2.12 \pm 0.51 \\
2.05 \pm 0.31 \\
2.05 \pm 0.31 \\
\end{array}$ \\
\hline
\end{tabular}

N (\%), frequency and percentage of patients; S- BC, Sinhalese Brief COPE scale; $\alpha$, Cronbach's alpha.

Table 2 Reliability and test-retest reliability of Brief COPE scale - phase 1 and 2 


\begin{tabular}{lcc}
\hline \multirow{2}{*}{ Brief COPE scale } & \multicolumn{2}{c}{ Time phase 1 and phase 2 } \\
\cline { 2 - 3 } & 1-2 Adaptive & 1-2 Maladaptive \\
Cronbach's alpha & 0.793 & 0.788 \\
Inter-Item correlation & 0.659 & 0.651 \\
Test re-test reliability & $0.657^{* *}$ & $0.651^{* *}$ \\
\hline
\end{tabular}

$\mathrm{p}<0.01^{* *}$

Table 3 Correlation between Brief COPE, CES-D, and WHOQOL-BREF

\begin{tabular}{|c|c|c|c|c|c|}
\hline & \multicolumn{4}{|c|}{ S-Brief COPE subscales } \\
\hline & & \multicolumn{2}{|c|}{ Adaptive coping } & \multicolumn{2}{|c|}{ Maladaptive coping } \\
\hline & & $\mathrm{r}$ & $\mathrm{p}$ & $\mathrm{r}$ & $\mathrm{p}$ \\
\hline \multirow{6}{*}{ Domains of WHOQOL- BREF } & CES-D & $-0.362^{*}$ & $<0.05$ & $0.349^{*}$ & $<0.05$ \\
\hline & Total QoL & $0.482^{* *}$ & $<0.01$ & -0.041 & 0.80 \\
\hline & Physical & $0.506^{* *}$ & $<0.01$ & -0.117 & 0.47 \\
\hline & Psychological & $0.338^{*}$ & $<0.05$ & 0.040 & 0.80 \\
\hline & Social & $0.328^{*}$ & $<0.05$ & -0.030 & 0.85 \\
\hline & Environmental & $0.415^{* *}$ & $<0.01$ & 0.029 & 0.85 \\
\hline
\end{tabular}

r, correlation coefficient; CES-D, Centre for Epidemiological Studies- Depression scale; QoL, Quality of Life; WHOQOL-BREF, World Health Organization Quality of Life- Brief scale; $\mathrm{p}<0.05^{*}$ and $\mathrm{p}<0.01^{* *}$

Table 4 Factor loadings and cross-loadings emerging from EFA of the Brief COPE 


\begin{tabular}{|c|c|c|c|c|c|c|c|}
\hline Items & F1 & F2 & F3 & F4 & F5 & F6 & F7 \\
\hline $\begin{array}{l}\text { BI've been refusing to believe } \\
\text { it it has happened. }\end{array}$ & -.992 & -.049 & -.068 & -.059 & .003 & -.010 & -.170 \\
\hline $\begin{array}{l}\text { BI've been blaming myself for } \\
\text { ngs that happened. }\end{array}$ & -.992 & -.049 & -.068 & -.059 & .003 & -.010 & -.170 \\
\hline $\begin{array}{l}\text { BI've been giving up the } \\
\text { empt to cope. }\end{array}$ & -.992 & -.049 & -.068 & -.059 & .003 & -.010 & -.170 \\
\hline $\begin{array}{l}\text { I've been looking for } \\
\text { mething good in what is } \\
\text { ppening. }\end{array}$ & -.992 & -.049 & -.068 & -.059 & .003 & -.010 & -.170 \\
\hline $\begin{array}{l}\text { AI've been giving up trying to } \\
\text { al with it. }\end{array}$ & -.992 & -.049 & -.068 & -.059 & .003 & -.010 & -.170 \\
\hline $\begin{array}{l}\text { BI've been using alcohol or } \\
\text { ler drugs to help me get } \\
\text { rough it. }\end{array}$ & -.800 & -.271 & -.021 & -.134 & -.374 & -.172 & -.218 \\
\hline $\begin{array}{l}\text { I've been trying to find } \\
\text { mfort in my religion or } \\
\text { iritual beliefs. }\end{array}$ & .200 & .858 & .089 & .390 & -.113 & .095 & .206 \\
\hline I've been learning to live with & .205 & .832 & .126 & .276 & .118 & -.038 & .191 \\
\hline $\begin{array}{l}\text { I've been thinking hard } \\
\text { out what steps to take. }\end{array}$ & -.214 & .741 & -.150 & .139 & .099 & .008 & -.077 \\
\hline $\begin{array}{l}\text { I've been praying or } \\
\text { ditating. }\end{array}$ & -.009 & .662 & .209 & .535 & -.147 & .092 & .329 \\
\hline $\begin{array}{l}\text { I've been trying to see it in a } \\
\text { ferent light, to make it seem } \\
\text { ore positive. }\end{array}$ & .202 & .658 & .136 & .592 & .125 & -.081 & .036 \\
\hline $\begin{array}{l}\text { I've been getting help and } \\
\text { vice from other people. }\end{array}$ & .332 & .574 & .448 & .362 & .050 & -.368 & .516 \\
\hline $\begin{array}{l}\text { I've been doing something to } \\
\text { nk about it less, such as } \\
\text { ing to movies, watching TV, } \\
\text { ydreaming, sleeping, or } \\
\text { opping. }\end{array}$ & -.101 & -.056 & .843 & .154 & -.096 & -.044 & .163 \\
\hline $\begin{array}{l}\text { I've been accepting the } \\
\text { ality of the fact that it has } \\
\text { ppened. }\end{array}$ & .035 & .016 & -.779 & -.057 & -.019 & -.025 & .048 \\
\hline $\begin{array}{l}\text { I've been getting emotional } \\
\text { pport from others. }\end{array}$ & .443 & .229 & .677 & .217 & -.187 & .250 & .550 \\
\hline $\begin{array}{l}\text { I've been trying to get advice } \\
\text { help from other people about } \\
\text { lat to do. }\end{array}$ & .483 & .438 & .616 & .308 & .267 & -.174 & .412 \\
\hline $\begin{array}{l}\text { I've been concentrating my } \\
\text { orts on doing something } \\
\text { out the situation I'm in. }\end{array}$ & -.024 & .319 & .131 & .910 & .044 & .093 & .123 \\
\hline $\begin{array}{l}\text { I've been turning to work or } \\
\text { ler activities to take my mind } \\
\text { things. }\end{array}$ & .162 & .206 & .172 & .862 & .088 & .150 & .036 \\
\hline $\begin{array}{l}\text { I've been trying to come up } \\
\text { th a strategy about what to }\end{array}$ & -.044 & .516 & .105 & .592 & -.317 & -.190 & .213 \\
\hline $\begin{array}{l}\text { A I've been using alcohol or } \\
\text { ler drugs to make myself feel }\end{array}$ & -.009 & -.387 & .165 & -.043 & -.685 & -.272 & -.203 \\
\hline
\end{tabular}


tter.

$\begin{array}{lllllllll}\text { A I've been saying things to } & & .102 & .026 & .236 & .429 & .665 & -.265 & .199\end{array}$ my unpleasant feelings

zape.

$\begin{array}{llllllll}\text { A I've been criticizing myself. } & .033 & -.005 & .046 & .180 & .032 & .782 & -.045\end{array}$

$\begin{array}{llllllll}\text { B I've been expressing my } & .006 & -.294 & .053 & -.104 & .280 & -.181 & .660\end{array}$ gative feelings.

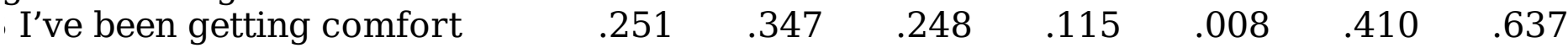

d understanding from

meone.

$\begin{array}{llllllll}\text { I've been taking action to try } & .364 & .476 & .036 & .480 & -.120 & -.125 & .593\end{array}$ make the situation better.

$\begin{array}{llllllll}\text { Eigenvalues } & 7.25 & 4.68 & 2.31 & 1.56 & 1.46 & 1.29 & 1.08\end{array}$

Variance explained $29.01 \% \quad 47.77 \% \quad 57.04 \% \quad 63.31 \% \quad 69.16 \% \quad 74.33 \% \quad 78.68 \%$

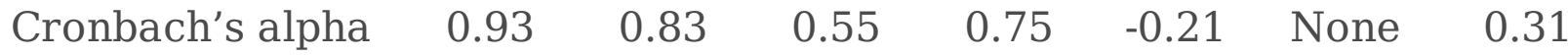

Extraction and Rotation Method, PCA and Oblimin with Kaiser Normalization; F1, Avoidance/ Behavioral disengagement; F2, Religion/Acceptance; F3, Seeking support; F4, Planning; F5, Substance use/Venting; F6, Self-blame; F7, Active/positive coping; Bold figures, items with mostly similar factor loadings.

\section{Figures}




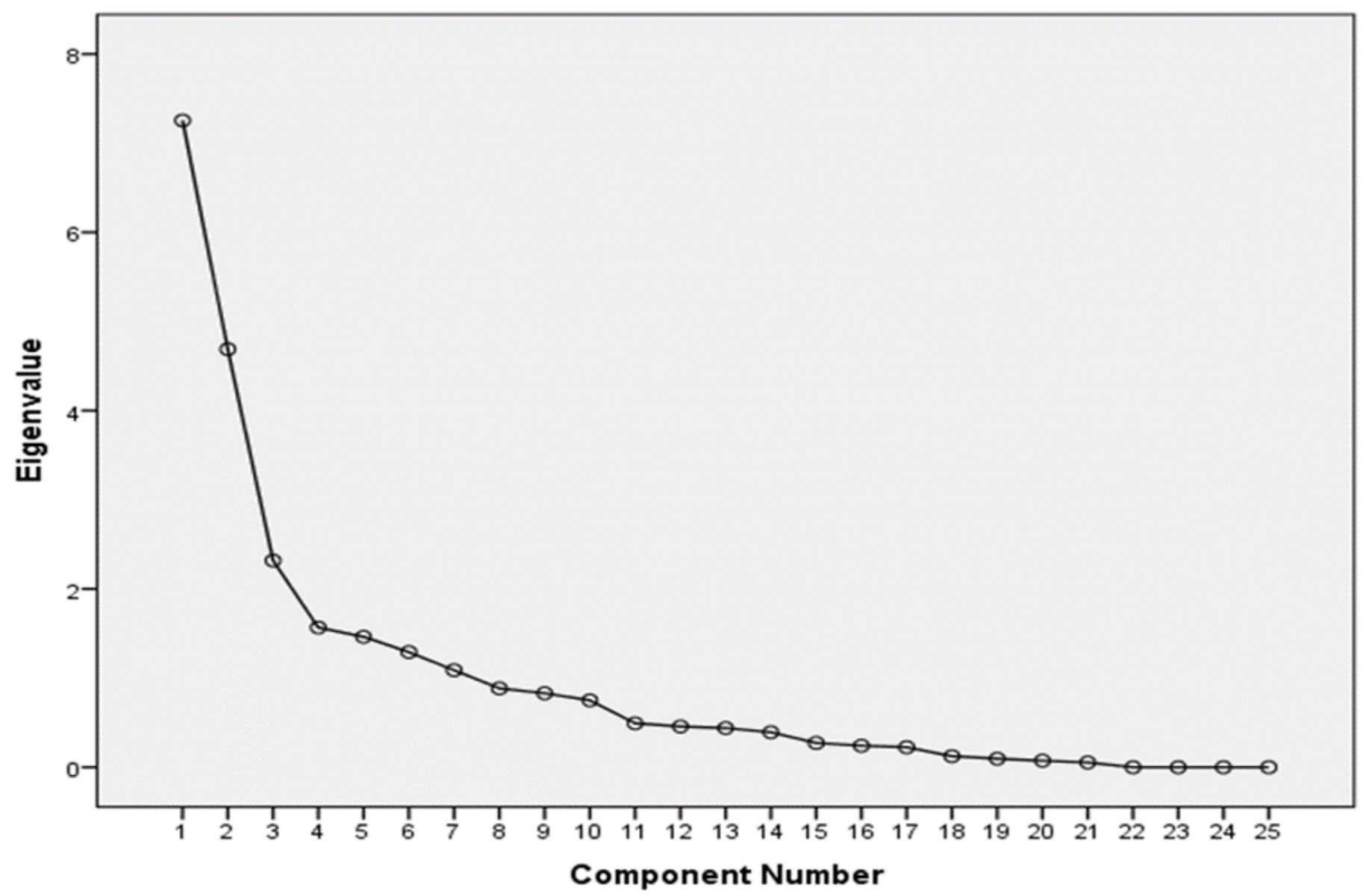

Figure 1

The scree plot - Brief COPE

\section{Supplementary Files}

This is a list of supplementary files associated with this preprint. Click to download.

- Additionalfile1SinhaleseversionofBriefCOPE.pdf 